\title{
Karayolu ulaşımında yakıt tüketimine bağlı karbon ayak izi değişimi: Çanakkale örneği
}

\author{
Change of carbon footprint due to fuel consumption: Çanakkale case study
}

\author{
Melike YALILI KILIÇ*1,a, Tarık DÖNMEZ ${ }^{1, b}$, Sümeyye ADALI ${ }^{1, c}$ \\ ${ }^{1}$ Bursa Uludă̆ Üniversitesi, Mühendislik Fakültesi, Çevre Mühendisliği Bölümü, 16059, Bursa
}

• Geliş tarihi / Received: 27.12.2020 • • Düzeltilerek geliş tarihi / Received in revised form: 02.06.2021 • Kabul tarihi / Accepted: 12.06 .2021

Öz

Etkileri gün geçtikçe artarak devam eden küresel 1sınmayla mücadele noktasında sera gazı emisyonlarının azaltılması büyük önem arz etmektedir. Kyoto Protokolünde ele alınan bu sorunun çözümünde karbon salınımlarının mümkün olan en düşük seviyeye indirilmesi tavsiye edilmiştir. Bu protokolle, karbon emisyonlarını doğru bir şekilde hesaplayabilmek amacıyla ülkelere emisyon salınım kotaları getirilmiştir. Kota değerlerine uyum noktasında sera gazı envanteri oluşturulması ve emisyonların karbon ayak izlerinin hesaplanması gerekmektedir. Karbon ayak izi, üretilen sera gazı miktarı açısından insan faaliyetlerinin çevreye verdiği zararın bir ölçüsüdür. Bu çalı̧̧mada, Çanakkale'de karayolu araçlarından kaynaklanan 2015-2018 yılları arasındaki karbon ayak izi hesaplanmıştır. Hükümetler Arası İklim Değişikliği Paneli (IPCC) tarafından önerilen Tier 1 ve Tier 2 yaklaşımının kullanıldığı hesaplamalarda Tier 1 yaklaşımında 2015 yılında $701.435 \mathrm{Gg}$ bulunan karbon ayak izi miktarı, 2018 yılında \%7'nin üzerinde bir artışla 752.536 Gg'a; Tier 2 yaklaşımında ise 2015 yılında 686.85 Gg olan karbon ayak izi miktarı, 2018 yılında 736.89 Gg'a yükselmiştir.

Anahtar kelimeler: Çanakkale, IPCC metodolojisi, Karbon ayak izi, Sera gazları, Yakıt türleri.

\begin{abstract}
The daily streamflow values have a great influence on the design and operation of water structures. Development of a method capable of predicting future short-time current flow providing control of water structures in operation, hydroelectricity generation, environmental protection and flood control can provide appropriate management for producers, users and the people of the region. In this study, the Haldizen Stream streamflow values were estimated using Multivariable Adaptive Regression Splines (MARS) and compared with the result of Classical Regression Analysis (CRA). For this purpose, daily flow data measured between 1998 and 2009 of the Haldizen Stream Şerah Stream Observation Station located in the Eastern Black Sea Basin were used. With this study, it is concluded that the result of MARS method give a better than those of KRA method and can be used in estimating flow values. This study is thought to be useful in energy planning on the river and also in the design of water conservation plans planned to be made in the region.
\end{abstract}

Keywords: Çanakkale, IPCC methodology, Carbon footprint, Greenhouse gases, Fuel types

\footnotetext{
*aa Melike YALILI KILIÇ; myalili@uludag.edu.tr, Tel: (0224) 29421 17, orcid.org/0000-0001-7050-6742

${ }^{\mathrm{b}}$ orcid.org/0000-0002-7313-5876 $\quad{ }^{\mathrm{c}}$ orcid.org/0000-0002-5077-7358
} 


\section{Giriş}

Dünya nüfusunun hızlı bir şekilde artmasıyla birlikte insanların ihtiyaçları da artmakta ve çeşitli sorunlar ortaya çıkmaktadır. Özellikle sanayi devrimi ile üretimin artması, doğal kaynakların tüketilmesine ve çevre kirliliğinin daha fazla hissedilmesine neden olmuştur. Kirlenme etkilerinden biri de atmosferik doğal dengedeki olumsuz değişimlerdir. İnsan faaliyetleri neticesinde meydana gelen karbondioksit, metan ve diazot oksit gibi sera gazları dünyadaki sicaklığın yükselmesine neden olmakta ve küresel isınma olarak tanımlanan bir problem ortaya çıkmaktadır (Açıkgöz, 2010). Küresel 1sınmaya bağlı iklim değişiklikleri, dünya üzerindeki yaşamı olumsuz yönde etkilemektedir (Aliusta vd., 2016).

İklim değişikliğinin yol açacağı felaketlerin farkına varılmasıyla beraber, sorunun çözümüne yönelik uluslararası platformda önemli gelişmeler yaşanmıştır. 1992'de Birleşmiş Milletler önderliğinde yapılan Rio Zirvesinde ülkelerin sera gazı salınımlarını azaltmak amaciyla önlemler alması gerektiği gündeme getirilmiş ve zirve sonrasında Birleşmiş Milletler İklim Değişikliği Çerçeve Sözleşmesi (BMIDÇS) imzalanmıştır (Uysal Şahin, 2016). Bu sözleşmeye ek olarak 1997 yılında kabul edilen Kyoto Protokolünde, gelişmiş ülkelerin sera gazı salınımlarını 1990 y1lına göre $\% 5.2$ oranında azaltmaları öngörülmüsstür. Protokolde ana hedef, altı sera gazının (karbondioksit, metan, diazot oksit, sülfür heksaflorit, hidroflorokarbonlar ve Perflorokarbonlar) 2008-2012 y1lları arası beş yıllık ortalama emisyon değerlerinin azaltılmasıdır (Özmen, 2009). 2019 y1lına gelindiğinde protokolün ikinci taahhüt dönemi olan Doha Değişikliği'nde sera gazı emisyonlarının 2020 yılına kadar 1990 yılına göre \%18 azaltılması kararlaştırılmıştır. Bu doğrultuda protokolde adı geçen ülkeler, müzakereler sonucunda farklı oranlarda sera gazı emisyon azaltımı yükümlülüklerini kabul etmişlerdir. Kyoto Protokolü resmi olarak 16 Şubat 2005 tarihinde yürürlüğe girmiş olup, protokole günümüzde 191 ülke ve $A B$ taraftır (T.C. Dışişleri Bakanlığı, 2020). Protokolde sera gazlarının azaltılması amacıyla alınabilecek önlemler arasında;

- Enerji verimliliği,

- Yenilenebilir enerji teknolojilerinin geliştirilmesi,
- Sürdürülebilir tarımın geliştirilmesi,

- Metan emisyonlarının geri kazanımı,

- Sera gazı emisyonlarının azaltımı,

- Yüksek miktarda $\mathrm{CO}_{2}$ tutulumunu sağlayan orman, bitki örtüsü vb. korunması ve yaygınlaştırılması yer almaktadır (Özmen, 2009).

Kyoto protokolünden sonra 4 Kasım 2016 tarihinde yürürlüğe giren Paris Antlaşmasında iklim değişikliğiyle mücadelenin önemi vurgulanmış, iklim eylem planlarının yerel toplulukların ihtiyaçları doğrultusunda oluşturulması gerektiği belirtilmiştir (Arı ve Aydın, 2019).

Çevre kirliliğinin önemli bir bölümünü oluşturan hava kirliliğinde, farklı etmenler bir arada bulunmasına rağmen en önemli etmen yanma olaylarıdır (Kelen, 2014). Yanma olayları orman ve bitki örtüsü yangınları, volkanlar gibi doğal kaynakl1; evsel 1sınma, endüstriyel faaliyetler ve motorlu taşıt kullanımı ile antropojenik kaynaklı olarak meydana gelmektedir (Sümer, 2014). Antropojenik kaynakların çoğu fosil tabanlı olup, özellikle motorlu taşıtlarda kullanılan fosil yakıtların eksik yanması sonucu kükürt ve kurşun bileşenleri, partikül maddeler, aldehit, keton, azot oksitler ve yanmamış hidrokarbonlar gibi farklı kirletici unsurlar meydana gelmektedir (Alkaya ve Yildırım, 2000; Kelen, 2014). Bu kirletici unsurlar insan ve çevre üzerinde toksik etki oluşturmaktadır. $\mathrm{Bu}$ durum taşıtlardan kaynaklanan emisyonların kontrolünü zorunlu kılmaktadır (Kelen, 2014).

Hava kirliliğinin korunması noktasında mevcut sorunlarının çözümüne yönelik uygulamalarda "Kyoto Protokolü" ile büyük başarı elde edilmiştir. Protokol ile belirlenen hava kirletici sinır değerlerin aşılmaması, sera gazı emisyonlarına sebep olan emisyonların karbon ayak izinin hesaplanması, sera gazı envanterlerinin hazırlanması ve bu sinırların altında kalacak çalışmaların ne kadar gerekli olduğu üzerinde durulmuştur (Türkay, 2018).

Kyoto Protokolü'ndeki sera gazlarının simgeleri, adları ve karbondioksit eşdeğeri olarak küresel 1sinma potansiyelleri (Global Warming Potential, GWP) Tablo 1'de verilmiştir. 
Tablo 1. Sera gazlarının karbondioksit eşdeğeri olarak küresel ısınma potansiyeli (Bekiroğlu, 2016)

\begin{tabular}{ll}
\hline Sera gazı & $\mathrm{CO}_{2}$ eşdeğeri olarak küresel isınma potansiyeli \\
\hline $\mathrm{CO}_{2}$ (Karbondioksit) & 1 \\
$\mathrm{CH}_{4}$ (Metan) & 21 \\
$\mathrm{~N}_{2} \mathrm{O}$ (diazot oksit) & 310 \\
$\mathrm{HFCs}$ (Hidroflorokarbonlar) & $140-11700$ \\
$\mathrm{PFCs}$ (Perflorokarbonlar) & $6500-9200$ \\
$\mathrm{SF}_{6}$ (Sülfür Heksaflorür) & 23900 \\
\hline
\end{tabular}

$\mathrm{CO}_{2}$ eşdeğerleri göz önüne alındığında, $\mathrm{SF}_{6}$ 'ün en yüksek $\mathrm{CO}_{2}$ eşdeğerine sahip olduğu, bu nedenle yayılımının azaltımı noktasında oluştuğu kaynağın kullanımına özellikle dikkat edilmesi gereken bir gaz olduğu görülmektedir. $\mathrm{CO}_{2}$ en zararsız sera gazı gibi gözükmesine rağmen, miktar olarak bakıldığında diğer sera gazlarına oranla yüksek seviyede olduğundan büyük bir tehlike potansiyeli taşımaktadır (T.C. Çevre ve Şehircilik Bakanlığı, 2020). $\mathrm{CO}_{2}$ hariç, diğer sera gazlarının aynı miktar $\mathrm{CO}_{2}$ 'e kiyasla ne kadar fazla is1 tutabilme kapasitesine sahip olduğu $\mathrm{CO}_{2}$ eşdeğeri ile tanımlanır. Üretilen sera gazı miktarının birim $\mathrm{CO}_{2}$ cinsinden ölçüsü ise karbon ayak izidir. Karbon ayak izinin belirlenmesi; birim $\mathrm{CO}_{2}$ eşdeğeri cinsinden toplam sera gazı emisyonlarının ifade edilmesi ile yapılmaktadır (Atabey, 2013).

Literatür incelendiğinde pek çok farklı alanda karbon ayak izi ile ilgili çalışmaların yapıldığ 1 görülmektedir. Bunlardan bazıları, ulaştırma ve karayollarında (B1y1k, 2018; Türkay, 2018; Ayan, 2019; Atabey, 2013), tekstilde (Doğan, 2019), geri kazanım tesislerinde (Demirbaş, 2018; Erdoğan, 2015; Arıc1, 2018), üniversitelerde (Gökçek vd., 2019; Kumaş vd., 2019; Binboğa ve Ünal, 2018; Özçelik, 2017; Turanlı, 2015), tarımsal üretimde (Şahin ve Onurbaş, 2016), atıksu arıtma tesislerinde (Güller, 2018) gerçekleştirilmiştir. Ülkemizde karayolu ulaşımından kaynaklı karbon ayak izi çalışmaları, Eskişehir (Türkay, 2018), Isparta (Bıy1k ve Civelekoğlu, 2020), Muğla (Ayan, 2019) ve Konya (Çelik, 2020) şehirlerinde 2018-2020 yıllarında gerçekleştirilmiştir.

Bu çalışmada, Çanakkale ilinin 2015-2018 yılları arasında karayolu ulaşımı kaynaklı karbon ayak izi, Hükümetler Arası İklim Değişikliği Paneli (IPCC) tarafindan önerilen ve Tier metoduyla belirlenen yöntemlerden olan Tier 1 ve Tier 2 metodları kullanılarak hesaplanmıştır.

\section{Türkiye ve Dünya'da karbon ayak izi}

Sera gazları doğal olarak atmosferde belirli oranlarda yer almakta olup, atmosferin yaklaşık $\% 1$ 'ini oluşturmaktadır. Atmosferin doğal bileşimi olan bu gazlar sayesinde güneşin yaydığ 1 1S1 dünyada belli oranda tutularak canlılar için uygun yaşam koşulları sağlanmaktadır (Doğan ve Tüzer, 2011). Sera gazları içerisinde yer alan $\mathrm{CO}_{2}$ havanın hacimce $\% 0.03$ 'ünü oluşturmakla birlikte doğadaki karbon döngüsünün en önemli bileşeni olup, yeşil bitkiler tarafindan fotosentetik olarak indirgenerek besin üretiminde rol oynamakta; bitki, mikroorganizma ve diğer canlılar tarafindan doğal olarak atmosfere geri salınmaktadır (Demir vd., 2015). Fakat sanayi devriminden itibaren birçok alanda enerji kaynağı olarak fosil yakıtların kullanımı, şehirleşme ve orman tahribatı sonucu atmosferde $\mathrm{CO}_{2}$ miktarında önemli derecede artış yaşanmış (Mısır vd., 2011); 1000-1750 yılları arasında atmosferdeki miktarı $280 \mathrm{ppm}$ olan $\mathrm{CO}_{2}$ konsantrasyonu 2000 yılında 368 ppm değerine ulaşmıştır (Doğan ve Tüzer, 2011).

Sanayileşmenin başlamasından günümüze kadar atmosferdeki $\mathrm{CO}_{2}$ konsantrasyonu yaklaşık \%40, $\mathrm{CH}_{4}$ oran1 2-2.5 kat, $\mathrm{N}_{2} \mathrm{O}$ oran1 ise \%15 seviyelerinde artış göstermiştir. Sanayileşmenin öncesinde organik maddelerin yapısal değişiklikleri ve bitkilerin solunumu sonucunda meydana gelen $\mathrm{CO}_{2}$ miktarı, insan kaynaklı üretilen $\mathrm{CO}_{2}$ miktarından çok daha fazla olmasına rağmen, sanayileşmenin artmasıyla birlikte $\mathrm{CO}_{2}$ miktarı gün geçtikçe artış göstermiş ve bu durum beraberinde birçok sorunu meydana getirmiştir (Pekin, 2006).

Karbon ayak izi, insan faaliyetleri neticesinde üretilen sera gazlarının birim $\mathrm{CO}_{2}$ cinsinden ölçüsüdür. Birincil karbon ayak izi ulaşım ve evsel enerji tüketimi dahil fosil yakitların yanmasından meydana gelen doğrudan $\mathrm{CO}_{2}$ emisyonlarının; ikincil karbon ayak izi ise, ürünlerin ham madde eldesinden nihai bertarafina kadar geçen sürede oluşan dolaylı $\mathrm{CO}_{2}$ emisyonlarının ölçüsüdür. 
İkincil karbon ayak izinin toplam karbon ayak izi içerisindeki payı \%54 civarındadır (Atabey, 2013).
Şekil 1'de kişi başı karbon ayak izi oluşum oranları yer almaktadir.

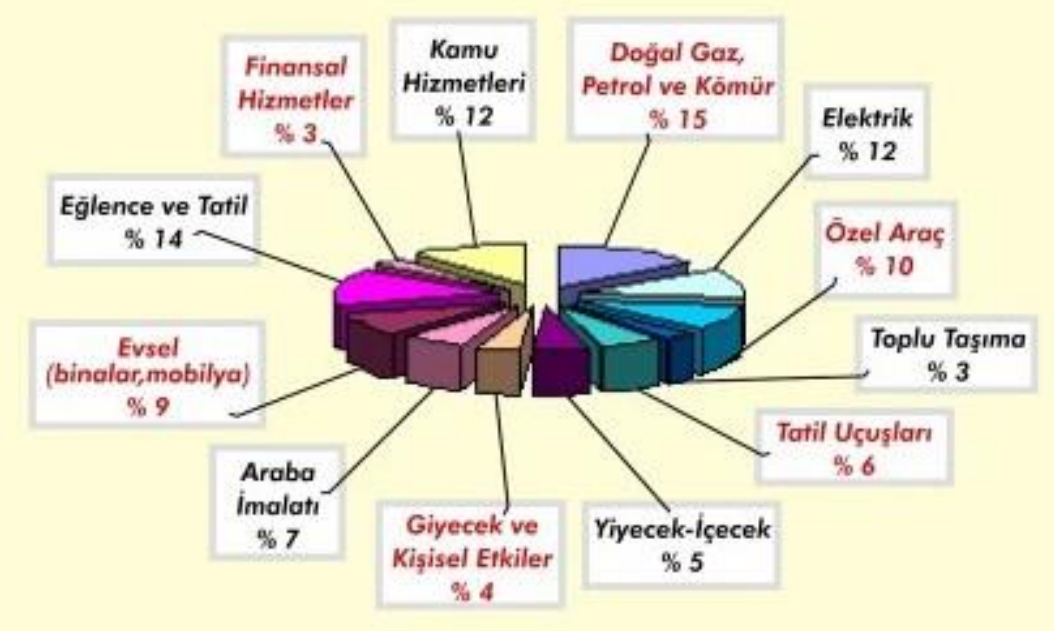

Şekil 1. Kişi başı karbon ayak izi oluşum oranları (Anonim, 2020a)

Sera gazlarından olan $\mathrm{CH}_{4}, \mathrm{H}_{2} \mathrm{O}, \mathrm{CO}_{2}$, ozon $\left(\mathrm{O}_{3}\right)$ ve $\mathrm{N}_{2} \mathrm{O}$ genellikle doğal süreçler içerisinde oluşmakta iken; HCFC, CFC ve tamamen florür bileşiği olan $\mathrm{SF}_{6}$ gibi gazlar ise antropojenik aktiviteler sonucu oluşmaktadır (IPCC, 1996). Belirtilen gazların haricinde; karbonmonoksit (CO), kükürt dioksit $\left(\mathrm{SO}_{2}\right)$, metan olmayan uçucu organik bileşikler (NMVOC), azot oksitler (NOx) ve yer seviyesindeki $\mathrm{O}_{3}$ kirletici gazlar olarak tanımlanabilen, direkt olarak küresel 1sınmaya neden olmayan, fakat dolaylı olarak küresel 1sınmayı etkileyen sera gazları olarak bilinmektedir (Uzunçakmak, 2014).

Dünya karbon atlasında 1960-2018 yılları arasını kapsayacak şekilde ülkelerin karbon ayak izi verileri kullanılarak G20 ülkeleri arasında yapılan değerlendirmede, 1990 yılında ABD, Rusya ve Çin karbon ayak izinde en yüksek değerlere sahip ilk üç ülke olarak belirtilirken; Endonezya, Türkiye ve Arjantin son üç sırada yer almıştır. Ancak 2018 yılında Çin, ABD ve Hindistan en yüksek değerlere sahip ilk üç ülke konumunda olup; İtalya, Fransa ve Arjantin ise son üç sırada yer almaktadır. Türkiye'de 2018 yılındaki karbon ayak izi değeri 1990 yılındaki değere göre yaklaşık 2.5 kat artış göstermiştir (Anonim, 2020b).

Literatürde ulaştırmaya dayalı sera gazı emisyonları hakkında çok sayıda çalışma bulunmaktadır. Biyık (2018) tarafindan yapılan çalışmada, Tier 1 ve Tier 2 metodu kullanılarak 2010-2016 yılları arasında Isparta ilindeki karayolu taşıtlarının akaryakıt kullanımları ele alınarak $\mathrm{CO}_{2}$ emisyonları hesaplanmıştır. 2010 yılında Tier 1 yaklaşım yöntemi ile hesaplanan $351.90 \mathrm{Gg}$ olan karayolu ulaşımından kaynaklı karbon ayak izi miktarı \%34 oranında artış göstererek 2016 yılında 471.84 Gg'a yükselmiştir. Aynı konuda yapılan diğer çalışmalar ise; Tier 1 metodu kullanılarak Türkay (2018) ve Ayan (2019) tarafindan gerçekleştirilmiştir. Türkay (2018) tarafindan Eskişehir ilinde 2012 ve 2017 yıllarında yapılan hesaplamalara göre, kara ulaşımı kaynaklı eşdeğer $\mathrm{CO}_{2}$ emisyonu 2012 y1l için $821.509 \mathrm{Gg}, 2017$ yılı için $1453.954 \mathrm{Gg}$ olarak belirlenmiştir. Muğla ilinde 2013-2018 yılları arasını kapsayan dönemde Ayan (2019) tarafından yapılan çalışmada karayollarında tüketilen yakıtların eşdeğer $\mathrm{CO}_{2}$ miktarı hesaplanmış olup, 2013 yılında 1023.845 $\mathrm{Gg}$ olan eşdeğer $\mathrm{CO}_{2}$ emisyonu, 2018 y1lında $1443.720 \mathrm{Gg}$ değerine yükselmiştir. Konya ilinde 2019 yılında Tier 2 metodu kullanılarak yapılan çalışmada, il geneli için ortalama $3918.85 \mathrm{Gg} \mathrm{CO}_{2}$ emisyonunun karayolu ulaşımından, $61.21 \mathrm{Gg} \mathrm{CO}_{2}$ emisyonunun demiryolu ulaşımından, $17.20 \mathrm{Gg}$ $\mathrm{CO}_{2}$ emisyonunun ise havayolu ulaşımından kaynaklandığı bildirilmektedir (Çelik, 2020).

\section{Materyal ve metot}

Bu çalışmada, Çanakkale ilinde karayolu ulaşımı kaynaklı fosil yakıt tüketiminin karbon salınımına etkisi değerlendirilmiştir. Öncelikle Tier 1 yöntemine göre Çanakkale'de kullanılan yakıt miktarları incelenerek, yakıt tüketimine bağl1 karbon ayak izi değişimi hesaplanmıştır. Yakıt türlerinin karayolu ulaşımı dışında kullanılma durumu ihmal edilmiştir. Mevcut veriler T.C. Enerji Piyasası Düzenleme Kurumu (EPDK) Petrol 
ve LPG Piyasası Sektör Raporlarından alınmıştır. Hesaplamalar IPCC'nin sunduğu Tier I ve Tier 2 metodu kullanılarak 2015-2018 y1llarını kapsayacak şekilde yapılmıştır.

IPCC, Birleşmiş Milletlere bağlı iki kurum olan Birleşmiş Milletler Çevre Programı (UNEP) ve Dünya Meteoroloji Örgütü (WMO)'nün ortak girişimiyle kurulmuştur. IPCC kapsamında, insan faaliyetlerinin iklim değişikliğine etkisini değerlendirmek üzere bilimsel kuruluşlar, enstitüler ve bilim insanlarının katkılarıyla iklim değişikliği değerlendirme raporları hazırlanmaktadır. 1990 yılında ilk raporu yayınlanmaya başlayan panelde son olarak 20132014 yıllarında 5. rapor yayınlanmıştır. IPCC raporları başlıca 4 bölümden oluşmaktadır:

- Değerlendirme raporları

- Özel raporlar

- Yöntem metodları

- BM dişı dillere çeviriler (Atabey, 2013; T.C. Çevre ve Şehircilik Bakanlığı, 2019).

Ülkelerin sera gazı emisyon hedeflerini gerçekleştirmek, ulusal envanterlerini geliştirmek, yayınlamak ve sera gazı emisyon envanterlerinde kıyaslamalı metodolojiler kullanmasını sağlamak amacıyla IPCC kılavuzu oluşturulmuştur. Üç kitaptan oluşan k1lavuzun birincisinde ulusal envanter oluşturmak amaciyla verilerin nasıl toplanıp-değerlendirileceği, çalışma sonuçlarının bildirilme şeklini içeren raporlama bilgileri yer almaktadır. İkinci kitap, raporlama çalışmalarında kullanılacak tabloları içeren ve yapılacak hesaplamalar hakkında açılamalar içeren bir çalışma kitabı niteliğindedir. Üçüncü kitap ise, uygulanabilecek metotları açıklayan, elde edilemeyen veriler yerine uygun olarak kullanılabilecek ortalama değerler içeren bir referans kitaptır (Pekin, 2006). IPCC'de sera gazı envanter hesaplamaları enerji, endüstriyel işlemler, solvent ve diğer ürünlerin kullanımı, tarım, atıklar, orman ve yeryüzü coğrafyasının kullanımı, genel rehberlik ve raporlama ana başlıkları adı altında incelenmiștir (Babaoğlu ve Özgünoğlu, 2017).

Ulaştırma sektörü kaynaklı emisyonlar yakıt yanmasıyla ilgilidir. Sera gazları içerisinde $\mathrm{CO}_{2}$ gazı doğrudan yakıtın yakılmasıyla bağlantılı bir gaz olduğundan dolayı diğer gazlardan farklı olarak daha kesin hesaplanabilmektedir. $\mathrm{CO}_{2}$ emisyonları, yakıtların satış veya tüketim değerleri kullanılarak birkaç düzeltme yapılarak bulunabilmektedir (Atabey, 2013). $\mathrm{CO}_{2}$ gazından farklı olarak, $\mathrm{CH}_{4}, \mathrm{~N}_{2} \mathrm{O}, \mathrm{NO}_{\mathrm{X}}, \mathrm{CO}$ ve $\mathrm{NMVOC}$ gazlarının hesabında daha detaylı bilgi istenmektedir. Yanma koşulları ve teknolojisi, emisyon standartları, yakıt karakteristikleri gibi çeşitli faktörlerin bilinmesi gerekmektedir. $\mathrm{Bu}$ aşamada "Tier" kavramları öne çıkmaktadır (Pekin, 2006).

IPCC kılavuzuna göre sera gazı emisyonlarından kaynaklanan karbon ayak izinin hesaplanmasında farklı Tier yaklaşımları bulunmaktadır: Tier 1, Tier 2 ve Tier 3 (Keskin vd., 2017).

Tier 1 Yaklaşımı: Yakıt tüketim verileri baz alınarak, yakıt türlerinin belirli emisyon faktörleriyle hesaplamaları yapılmaktadır. Yakıtın ne tür bir teknoloji ile yakıldığ önemsenmemektedir. Elde edilen sonuç $\mathrm{CO}_{2}$ değeri cinsinden ifade edilmektedir.

$\mathrm{CO}_{2}$ emisyonlarının hesabını yapabilmek amaciyla ilk olarak yakıt tüketim miktarları belirlenir. İkinci olarak, yakıtların tüketim miktarlarının IPCC Kılavuzu'nda bulunan dönüşüm faktörleriyle çarpılması ile yakıt türlerinin enerji muhtevası tespit edilmektedir. İlk adımda hesaplanmış olan yakıt kullanım miktarları eğer kütle türünden $(\mathrm{kg}$, ton) ise, net kalori değerlerine uygun olarak belirlenen dönüşüm faktörleriyle (TJ/kt veya TJ/ton ) çarpılarak TJ birimine çevrilir. Tablo 2'de yakıt türlerine ait dönüşüm faktörleri verilmiştir.

Tablo 2.Yakıt türlerine ait dönüşüm faktörleri (IPCC, 2006)

\begin{tabular}{lll}
\hline Yakıt türü & $\begin{array}{l}\text { Dönüşüm faktörü (TJ/Gg) } \\
\text { (Eşdeğer } \mathbf{C O}_{\mathbf{2}} \text { hesabı ) }\end{array}$ & $\begin{array}{l}\text { Dönüşüm faktörü (Tj/kt) } \\
\text { (Toplam } \mathbf{C O}_{\mathbf{2}} \text { hesabı ) }\end{array}$ \\
\hline Benzin & 44.3 & 44.8 \\
Dizel (Motorin) & 43 & 43.33 \\
LPG & 47.3 & 47.31 \\
\hline
\end{tabular}

Üçüncü adımda ise her bir yakıt türüne uygun olarak belirlenen $\mathrm{CO}_{2}$ emisyon faktörleri kullanılarak yakıtların içerdiği toplam $\mathrm{CO}_{2}$ miktarı tayin edilir. Tablo 3'de yakıt türlerinin $\mathrm{CO}_{2}$ emisyon faktörleri yer almaktadır. 
Tablo 3.Yakıt türlerinin $\mathrm{CO}_{2}$ emisyon faktörleri (IPCC, 2006)

\begin{tabular}{lll}
\hline Yakıt türü & Emisyon faktörü $(\mathbf{k g ~ C O} / \mathbf{T J})$ & Emisyon faktörü (t C/Tj) \\
\hline Benzin & 69300 & 18.9 \\
Dizel (Motorin) & 74100 & 20.2 \\
LPG & 63100 & 17.2 \\
\hline
\end{tabular}

Birincil Yakıtlar: Doğada bulundukları şekliyle kullanılabilen kömür, doğalgaz ve ham petrol gibi yakitlardir.

İkincil Yakıtlar: Birincil yakıtların işlenmesiyle elde edilen benzin, yağlayıcılar v.b. ürünler ikincil yakıtları oluşturmaktadır.

Yaklaşım türüne göre (birincil, ikincil) yakıt tüketim değerlerini aşağıdaki formülasyonları uygulayarak tespit etmek mümkündür.

Birincil Yakıt Tüketimi $=\mathrm{Im}+\mathrm{Pr}-\mathrm{Ex}-\mathrm{SC}-\mathrm{IB}$

İkincil Yakıt Tüketimi $=$ Im- SC - IB - Ex

(Im: İthal edilen yakıt miktarı, Pr: Üretilen yakıt miktarı, Ex: İhraç edilen yakıt miktarı,

SC: Stoklarda meydana gelen değişim, IB: Uluslararası kullanıma satılan yakıt miktarı)

Tier 2 Yaklaşımı: Bu yöntemde akaryakıt tüketimi yerine taşıtın yaptığı yol miktarı hesaba katılmaktadır. Tier 1 yöntemine göre daha ayrıntılı bir hesap yöntemi olan bu yöntemde, daha fazla veri gereksinimine ihtiyaç duyulmasına rağmen özellikle $\mathrm{CO}_{2}$ dışındaki gazların emisyonlarında daha doğru sonuçlar elde edilmektedir. Tier 2 yaklaşımının Tier 1 yaklaşımından en önemli farkı, akaryakıtın kullanıldığı yanma teknolojisi hakkında bilgi sahibi olmayı gerektirmesidir (Bıyık, 2018). Tier 2 yaklaşımında kullanılan yakıtlar gruplara ayrilarak uygun emisyon faktörleri kullanılarak hesaplamalar yapılmaktadır (Pekin, 2006).

Tier 2 yaklaşımında hesaplama 5 adımdan oluşmaktadır. 1. adımda taşıt türlerine göre ayrım yapılarak taşıtlar, kullandıkları akaryakıt türü ve emisyon kontrol teknolojisine göre sinıflandırılır. 2. adımda taşıt türü, kullanılan akaryakıt türü, emisyon kontrol teknolojisi ve hesabi yapılacak emisyon türüne göre emisyon faktörü belirlenir. 3 . adımda taşıt aktivitesi belirlenir. 4. adımda taşıt sayısı, yaptığı yol ve emisyon faktörü çarpılıp o gaza ait emisyon miktarı hesaplanır. 5. adımda belirlenen kriterlere göre sınıflandırılan taşıtlardan kaynaklanan aynı gaza ait diğer veriler toplanarak o gaza ait toplam emisyon miktarı bulunur. Eşitlik 1'de Tier 2 emisyon hesap modeli verilmiştir (IPCC, 2006; B1yık, 2018).

$\sum$ Emisyon $=\sum\left[\right.$ Aktivite $\left._{\mathrm{abc}} \times \mathrm{EF}_{\mathrm{abc}}\right]$

(Emisyon miktarı: (g), Aktivite, tüketilen enerji miktarı veya verilen mobil kaynağın kat ettiği yol uzunluğu: (km), EF (Emisyon faktörü): (g/km), a: Yakıt tipi (dizel, benzin, LPG vb.), b: Araç tipi (özel otomobil, hafif dizel, ağır dizel vb.), c: Emisyon kontrol teknolojisi (kontrolsüz, 15.04, Euro I, Euro III vb.)

Tier 3 Yaklaşımı: Yakıt istatistikleri ve yakma teknolojisine göre belirlenmiş teknolojiye bağlı emisyon faktörlerinin, daha fazla detaylı verilerin olduğu yakma tesislerinin 1sıl güçlerinin, beslenme tipi vb. bilgilerin kullanılarak yapıldığ hesaplamalardır (Atabey, 2013). Tier 3 yaklaşımında yakıtların tüketim değerleri yanında araçların aldıkları yol uzunluğu veya ton-km biriminde taşınan yük değerleri göz önüne alınarak, bunlara uygun emisyon faktörleri kullanılarak hesaplama yapılır (IPCC/UNEP/OECD/IEA, 1997; Pekin, 2006). Eşitlik 2'de Tier 3 emisyon hesap modeli verilmiştir (IPCC, 2006).

$\sum$ Emisyon $=\sum\left[\right.$ Mesafe $\left._{\text {abcd }} \times \mathrm{EF}_{\mathrm{abcd}}\right]+\sum \mathrm{C}_{\mathrm{abcd}}$

(Emisyon miktarı: $(\mathrm{kg}), \mathrm{EF}$ (emisyon faktörü): $(\mathrm{kg} / \mathrm{km})$, Mesafe, belirli bir mobil kaynak aktivitesi için termal olarak stabilize edilmiş motor çalıștırma aşamasında kat edilen mesafe (VKT): $(\mathrm{km}), \mathrm{C}$ : ısınma aşaması sırasında emisyonlar (soğuk çalıştırma) (kg), a: yakıt tipi, b: araç tipi, c: emisyon kontrol teknolojisi, d: çalıșma koşulları (kentsel veya kırsal yol türü, iklim veya diğer çevresel faktörler))

Tablo 4'te Tier 1 yöntemine göre eşdeğer $\mathrm{CO}_{2}$ emisyon miktarın belirlemede kullanılan birim ve formülasyonlar yer almaktadır. 
Tablo 4. Tier 1 yöntemine göre eşdeğer $\mathrm{CO}_{2}$ emisyon miktarını belirlemede kullanılan birim ve formülasyonlar (Bıyık ve Civelekoğlu, 2020)

\begin{tabular}{lll}
\hline Sembol & Birim & Formülasyon \\
\hline A & Yakıt Tüketimi (ton) & \\
B & Dönüşüm Faktörü (TJ/Gg) & $\mathrm{A}^{*} \mathrm{~B}^{*} 10^{-3}$ \\
$\mathrm{C}$ & Enerji Tüketimi (TJ) & \\
D & Emisyon Faktörü $(\mathrm{kg} / \mathrm{TJ})$ & $\mathrm{C}^{*} \mathrm{D}$ \\
$\mathrm{E}$ & Emisyon İçeriği $(\mathrm{kg})$ & $\mathrm{E}^{*} 10^{-6}$ \\
$\mathrm{~F}$ & Emisyon İçeriği $(\mathrm{Gg})$ & \\
$\mathrm{G}$ & Küresel Issinma Potansiyeli (t) & $\mathrm{G}^{*} \mathrm{~F}$ \\
$\mathrm{H}$ & $\mathrm{CO}_{2}$ emisyonu $\left(\mathrm{Gg} \mathrm{CO}_{2}\right)$ & \\
\hline
\end{tabular}

\section{Bulgular ve tartışma}

Çalışma kapsamında 2015 ve 2018 yılları arasında Çanakkale ilinde karayolu ulaşımı kaynaklı oluşan sera gazı emisyonları IPCC Tier 1 ve Tier 2 yöntemi ile hesaplanmıştır. 2015 ve 2018 yılları arasında nüfusta yaşanan artış ile birlikte gerek özel araç, gerekse toplu taşıma araçlarının sayısının artmasından dolayı, Çanakkale ilinde tüketilen yakıt miktarında da artış gözlenmiştir. Diğer yandan Çanakkale ili, turizm açısından zengin kaynaklara sahiptir. Bu nedenle nüfus yoğunluğu özellikle yaz mevsiminde artış göstermektedir. Tablo 5'te 2015-2018 döneminde Çanakkale ili karayollarında tüketilen yakıt miktarları verilmiştir.

Tablo 5. 2015-2018 döneminde Çanakkale İli Karayollarında Tüketilen Yakıt Miktarları (EPDK, 2020a, 2020b)

\begin{tabular}{llll}
\hline Yıllar & Benzin Türleri & Motorin Türleri & LPG (Otogaz) \\
\hline 2018 & 26519.57 ton & 185699.29 ton & 22019.266 ton \\
2017 & 25703.22 ton & 188844.75 ton & 21602.325 ton \\
2016 & 24413.87 ton & 181791.66 ton & 22206.395 ton \\
2015 & 22414 ton & 174663 ton & 21228 ton \\
\hline
\end{tabular}

Tablo 5 incelendiğinde, tüketilen benzin miktarının her geçen yıl artış gösterdiği görülmektedir. Yıllar arasında karşılaş̧ırma yapıldığında motorin tüketim miktarının 2017 yılında; LPG tüketim miktarının ise 2016 yılında en yüksek değere ulaştı̆̆ gözlenmiştir.

Şekil 2'de Tier 1 yöntemine göre hesaplanan yakıt türlerine ait eşdeğer $\mathrm{CO}_{2}$ emisyon miktarları görülmektedir. Eşdeğer $\mathrm{CO}_{2}$ emisyon miktarı en yüksek değerine 2017 yılında 758.895 gigagram ile (Gg), en düşük değerine ise 2015 yılında 701.435 Gg ile ulaşmıştır. 2017 yılında pik yapan emisyon değerlerinin, 2017 yılı içerisinde kullanılan motorin miktarının diğer y1llara oranla daha yüksek olması nedeniyle (Tablo 5) oluştuğu düşünülmektedir. 


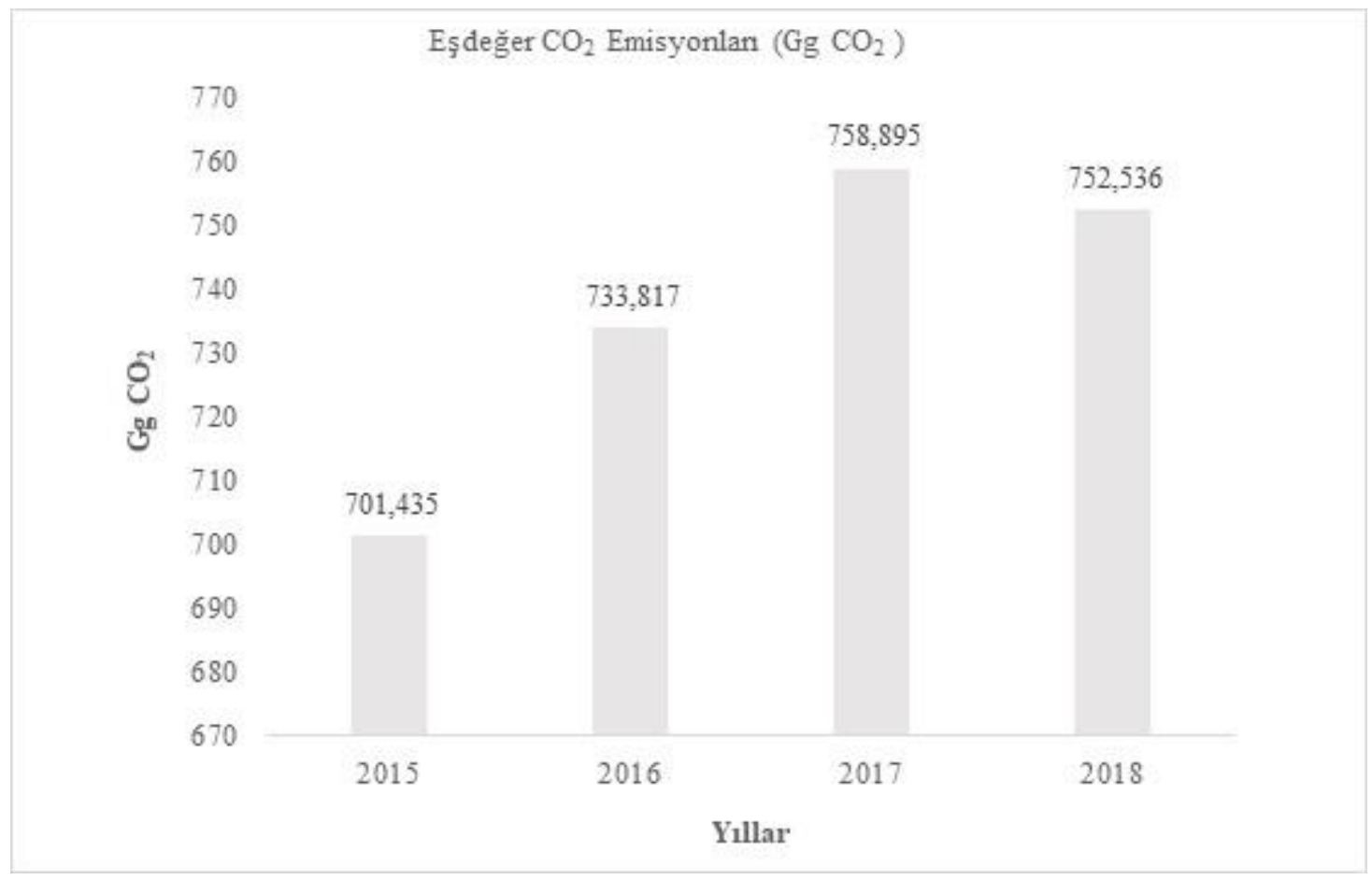

Şekil 2. Tier 1 yöntemine göre hesaplanan yakıt türlerine ait eşdeğer $\mathrm{CO}_{2}$ emisyon miktarları

Tier 2 hesaplamaları kapsamında Tablo 6'da Çanakkale ili trafiğe kayıtlı araç sayıları yer almaktadır.

Tablo 6. Çanakkale ili trafiğe kayıtlı araç sayıları (TÜİK, 2020)

\begin{tabular}{|c|c|c|c|c|c|c|c|c|c|}
\hline \multirow{2}{*}{ Yillar } & \multicolumn{3}{|c|}{ Otomobil } & \multirow{2}{*}{$\begin{array}{c}\text { Kamyon } \\
\text { Dizel }\end{array}$} & \multirow{2}{*}{$\begin{array}{c}\text { Kamyonet } \\
\text { Dizel }\end{array}$} & \multirow{2}{*}{$\begin{array}{c}\text { Minibüs } \\
\text { Dizel }\end{array}$} & \multirow{2}{*}{$\begin{array}{c}\text { Otobüs } \\
\text { Dizel }\end{array}$} & \multirow{2}{*}{$\begin{array}{c}\text { Motosiklet } \\
\text { Benzin }\end{array}$} & \multirow{2}{*}{$\begin{array}{c}\text { Traktör } \\
\text { Dizel }\end{array}$} \\
\hline & Dizel & Benzin & LPG & & & & & & \\
\hline 2015 & 24020 & 20980 & 30634 & 5319 & 27704 & 2219 & 1945 & 52765 & 30928 \\
\hline 2016 & 27928 & 22276 & 32583 & 5598 & 29910 & 2379 & 1987 & 54691 & 32119 \\
\hline 2017 & 31683 & 23180 & 34368 & 5866 & 31936 & 2524 & 1939 & 56860 & 33253 \\
\hline 2018 & 33769 & 22849 & 34778 & 5952 & 33220 & 2603 & 1911 & 58949 & 33909 \\
\hline
\end{tabular}

Araç sayıları elde edildikten sonra, her araç grubunun 100 km'deki yakıt tüketim miktarları belirlenir. Bunun için IPCC Kılavuzunda yer alan araç gruplarından seçim yapılır (IPCC/UNEP/OECD/IEA; 1997-2006). Bu şekilde emisyon standartları belirlenmiş olur. IPCC Kılavuzunda araç gruplarının ülkemiz için uygunluğu belirlenmiş olan yakıt tüketim değerleri Tablo 7'de yer almaktadır.

Tablo 7. Araç gruplarının 100 km'deki yakıt tüketimleri (litre/100 km)

\begin{tabular}{cccccccccc}
\hline \multirow{2}{*}{ Yıllar } & \multicolumn{3}{c}{ Otomobil } & Kamyon & Kamyonet & Minibüs & Otobüs & Motosiklet \\
\cline { 2 - 5 } & Benzin & Dizel & LPG & & & & & \\
\hline 2015 & 8.5 & 7.3 & 11.2 & 29.90 & 10.90 & 10.90 & 29.90 & 4.00 \\
2016 & 8.5 & 7.3 & 11.2 & 29.90 & 10.90 & 10.90 & 29.90 & 4.00 \\
2017 & 8.5 & 7.3 & 11.2 & 29.90 & 10.90 & 10.90 & 29.90 & 4.00 \\
2018 & 8.5 & 7.3 & 11.2 & 29.90 & 10.90 & 10.90 & 29.90 & 4.00 \\
\hline
\end{tabular}


Araçların 100 km'deki yakıt tüketimleri belirlendikten sonra, araç gruplarının bir yılda gittiği mesafenin belirlenmesi gerekmektedir. $\mathrm{Bu}$ değerleri elde etmek için kesin bir kaynak bulunmamakla birlikte, ülkemizdeki toplam yakıt tüketim değerleriyle bir yakıt dengesi oluşturacak şekilde, araç sayısı ve $100 \mathrm{~km}$ 'deki ortalama yakıt tüketim miktarları yardımıyla, araçların yıllık menzilleri ortalama değer cinsinden elde edilebilmektedir. $\mathrm{Bu}$ yaklaşıma göre hesaplanan araçların ortalama yıllık menzilleri Tablo 8'de verilmiştir.

Tablo 8. Araç gruplarının ortalama yıllık menzilleri $(\mathrm{km})$

\begin{tabular}{lcccccccc}
\hline Yıllar & \multicolumn{3}{c}{ Otomobil } & Kamyon & Kamyonet & Minibüs & Otobüs & Motosiklet \\
\cline { 2 - 7 } & Benzin & Dizel & LPG & & & & & \\
2015 & 3492 & 4276 & 5085 & 43247 & 16853 & 26127 & 43248 & 3697 \\
2016 & 3530 & 4425 & 5162 & 45735 & 17845 & 26396 & 44491 & 3766 \\
2017 & 3405 & 4654 & 5048 & 50114 & 18659 & 28172 & 50141 & 3817 \\
2018 & 3444 & 5090 & 5242 & 42791 & 16871 & 27077 & 48826 & 3960 \\
\hline
\end{tabular}

Elde edilen veriler kapsamında örnek olarak 2015 yılında benzinli otomobillerinden açığa çıkan $\mathrm{CO}_{2}$ emisyonu hesaplanmıştır.

Enerji Tüketimi $[\mathrm{TJ}]=$ Yakıt Tüketimi $[\mathrm{t}] \times 10^{-3} \times$ Dönüşüm Faktörü [TJ/kt]

Karbon İçeriği $[\mathrm{t} \mathrm{C}]=$ Karbon Emisyon Faktörü $[\mathrm{t}$ $\mathrm{C} / \mathrm{TJ}] \times$ Enerji Tüketimi [TJ]

Karbon İçeriği $[\mathrm{Gg} \mathrm{C}]=$ Karbon İçeriği $[\mathrm{t} \mathrm{C}] \times 10^{-3}$ Karbon Emisyonu [Gg C] = Karbon İçeriği [Gg C]

$\times$ Karbon Oksitlenme Oran 1 $\mathrm{CO}_{2}$ Emisyonu $\left[\mathrm{Gg} \mathrm{CO}_{2}\right]=$ Karbon Emisyonu [Gg C] $\times(44 / 12)$

Otomobil benzin yakit tüketimi $2015=6227.284 \mathrm{t}$ $\times 10^{-3}=6.23$
Dönüşüm Faktörü $=44.80 \mathrm{TJ} / \mathrm{kt}$

Enerji Tüketimi $=6.23 \times 44.80=279.10 \mathrm{TJ}$

Benzinin Karbon Emisyon Faktörü $=18.9$ t C/TJ

Karbon İçeriği $=279.10 \times 18.9=5274.99$ t C

Karbon İçeriği $=5274.99 \times 10^{-3}=5.28 \mathrm{Gg} \mathrm{C}$

Benzinin Karbon Oksitlenme Oran $1=0.99$

Gerçek Karbon Emisyonu $=5.28 \times 0.99=5.23$

$\mathrm{GgC}$

$\mathrm{CO}_{2}$ Emisyonu $=5.23 \times 44 / 12=19.15 \mathrm{Gg} \mathrm{CO}_{2}$

Tablo 9'da karayollarında oluşan $\mathrm{CO}_{2}$ emisyonlarının araç gruplarına göre dağılımı verilmiştir.

Tablo 9. Karayollarında oluşan $\mathrm{CO}_{2}$ emisyonlarının araç gruplarına göre dağılımı

\begin{tabular}{ccccccccc}
\hline Yıllar & \multicolumn{3}{c}{ Otomobil } & Kamyon & Kamyonet & Minibüs & Otobüs & Motosiklet \\
\cline { 2 - 5 } & Benzin & Dizel & LPG & & & & & \\
2015 & 19.15 & 24.78 & 51.80 & 218.53 & 161.72 & 20.08 & 81.34 & 24.44 \\
2016 & 20.56 & 28.69 & 56.11 & 243.37 & 184.91 & 21.92 & 84.20 & 25.36 \\
2017 & 20.75 & 34.31 & 57.89 & 279.28 & 206.52 & 24.78 & 92.46 & 26.74 \\
2018 & 20.59 & 40.03 & 60.86 & 242.26 & 194.13 & 24.46 & 88.96 & 28.89 \\
\hline
\end{tabular}

Çanakkale ilinde 2015-2018 döneminde karayollarında bulunan araçlara ait $\mathrm{CO}_{2}$ salınım miktarları incelendiğinde, en yüksek salınımın kamyon tipi araçlardan, en düşük salınımın ise benzinli otomobillerden yayıldığı görülmektedir. Şekil 3'te Tier 2 yöntemine göre hesaplanan eşdeğer $\mathrm{CO}_{2}$ emisyon miktarları yer almaktadır. 


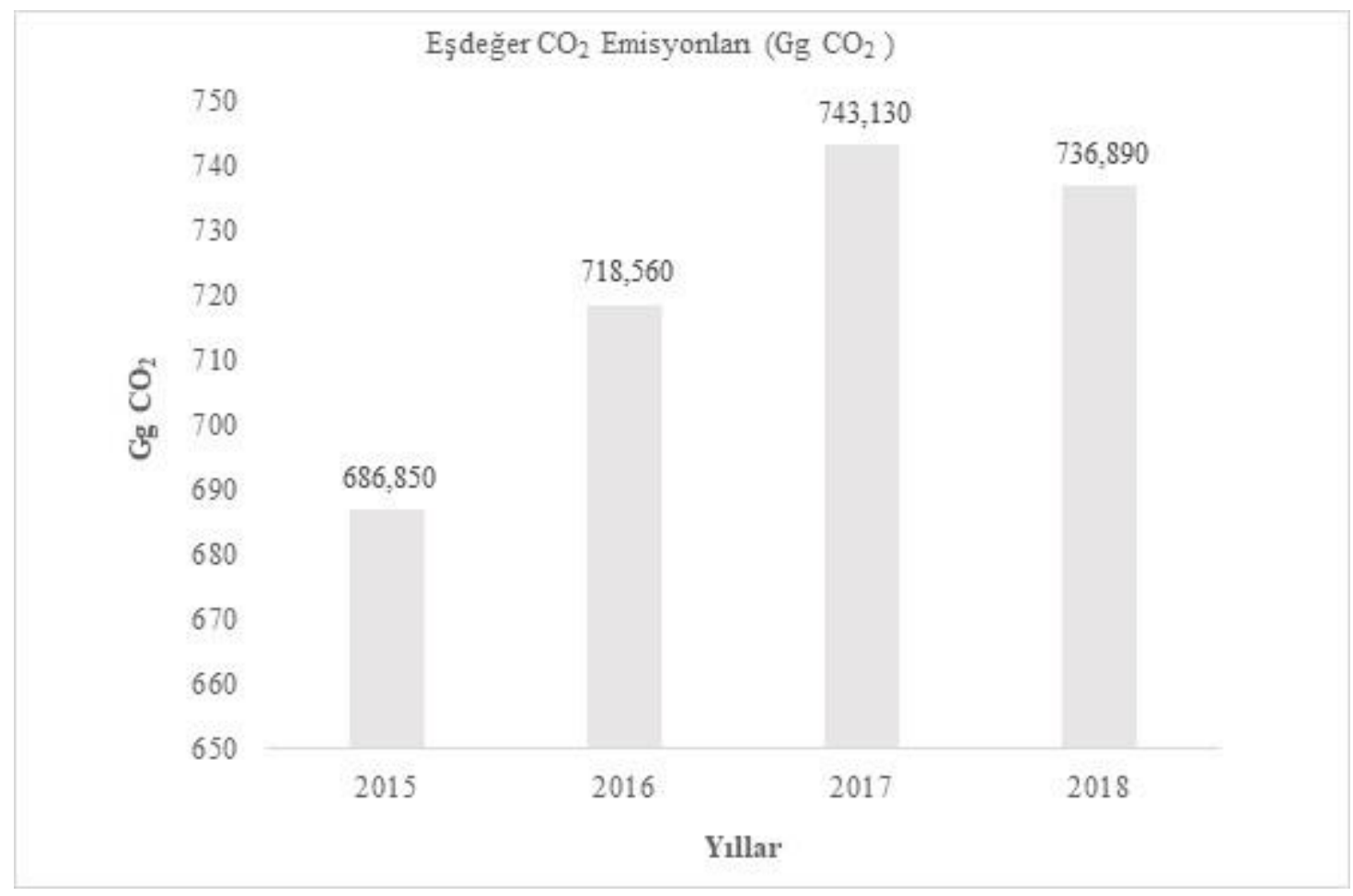

Şekil 3. Tier 2 yöntemine göre hesaplanan eşdeğer $\mathrm{CO}_{2}$ emisyon miktarları

Şekil 3 incelendiğinde, Tier 2 yöntemine göre yapılan hesaplamalar sonucu 2015 yılı eşdeğer $\mathrm{CO}_{2}$ emisyonu miktarı 2015 yılında 686.85 Gg'la en düşük, 2017 yılında 743.13 Gg'la en yüksek değerine ulaşmıştır. Tier 1 ve Tier 2 yöntemleriyle yapılan hesaplamalar karşılaştırıldığında, elde edilen sonuçların birbirleriyle orantılı olarak değişim gösterdiği görülmektedir (Şekil 4). Bununla birlikte Tier 2 yöntemi daha ayrıntılı bir veri analizini gerektirdiği için Tier 2 yöntemi kullanılarak ulaşılan sonucun gerçeğe daha yakın olduğu bildirilmektedir (Bıyık, 2018).

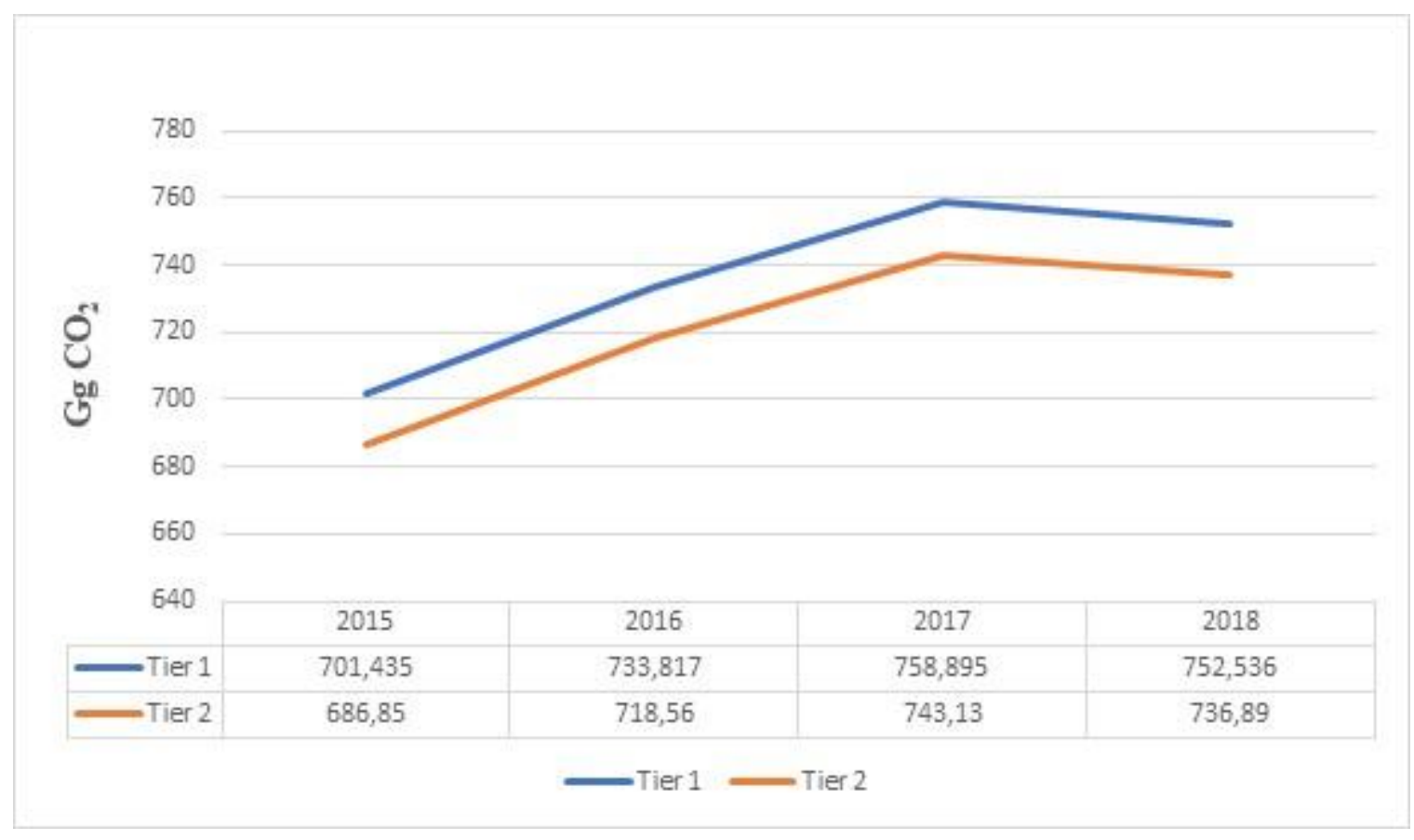

Şekil 4. Tier 1 ve Tier 2 hesaplarının yıl bazında karşılaştııılması

$\mathrm{Bu}$ çalışmaya benzer olarak, Isparta'da Tier 1 ve Tier 2 yaklaşım yöntemi kullanılarak yapılan çalışmada, Tier 1 yöntemiyle 2010 yılında 351.90 Gg olarak hesaplanan karayolu ulaşımı kaynaklı 
$\mathrm{CO}_{2}$ emisyon değeri, 2016 yılında \%34'lük bir artış göstererek $471.84 \mathrm{Gg}$ 'a ulaşmış; Tier 2 yöntemiyle yapılan hesaplamalarda ise 2010 yılinda $1605 \mathrm{Gg}$ olan emisyon değeri 2016 y1lında \%43'lük artış göstererek 2292 Gg'a yükselmiştir (Bıyık, 2018). Atabey (2013) tarafindan Diyarbakır ilinde 20102012 yıllar1 arasında farklı sektörlerde oluşan karbon ayak izini belirlemek için yapılan çalışmada, karayolu ulaşımından kaynaklanan $\mathrm{CO}_{2}$ emisyon miktarı Tier 1 yöntemiyle yapılan hesaplamalar sonucu 2010 yılı için $492.97 \mathrm{kt}$ (kiloton), 2011 y1lı için 526,3 kt, 2012 yılı için $570.2 \mathrm{kt}$ olarak belirlenmiştir.

\section{Sonuçlar}

Enerjinin üretimi ve kullanımı başta olmak üzere birçok farklı kaynaktan atmosfere yayılan sera gazları, küresel ısınmada önemli bir etkiye sahiptir. Ulaşım sektörü de sera gazı yayılımının artışında büyük bir paya sahip olup; benzin, motorin, LPG gibi yakıtların günümüzde hala yoğun olarak kullanıliyor olmasi nedeniyle karbon emisyonlarının artışını devam ettirmektedir.

$\mathrm{Bu}$ çalışmada, Çanakkale ili için 2015-2018 döneminde karayolu ulaşımında kullanılan benzin, motorin ve LPG tipi yakıtların oluşturduğu karbon emisyonu incelenmiştir. Yapılan incelemeler sonucunda, yakıtlar arasında en büyük tüketim payının motorinde, en yüksek karbon emisyonunun motorin tüketiminin zirveye ulaştığı 2017 yılında oluştuğu belirlenmiştir.

Atmosfere salınan sera gazlarının artışı, iklim değişikliğinin en önemli nedeni olarak gösterilmektedir. Günümüzde etkilerini hissetmeye başladığımız iklim değişikliği ileriki dönemde etkilerinin artışına bağlı olarak çevre ve insan sağlığı üzerinde çok daha büyük bir tehdit oluşturma potansiyeli taşımaktadır. Sera gazı yayılımının kontrol altına alınması günümüzde yaşam kalitesinin artması ve gelecek nesillere daha yaşanabilir bir dünya bırakma noktasında önemli bir adım olacaktır.

Yakıt tüketiminin düşürülmesi ve taşıtların çevreye verdiği zararların azaltılması amacıyla günümüzde içten yanmalı motorlara sahip araçlarda bulunan elektrik motorlarının kendi enerjisini üretebilmesini sağlayan hibrit teknolojisine sahip araçlar piyasada yerini almaya başlamıştır. Hibrit araç kullanımının yaygınlaşmasının taşıt kaynaklı karbon salınımının azaltılması noktasında büyük bir adım olacağı öngörülmektedir.
Taşıt kaynaklı karbon salınımının azaltılması amacıyla alınabilecek önlemler arasında;

- Çevreci motor teknolojilerinin geliştirilmesi ve özendirilmesi,

- Karayolları yakınlarında ağaçlandırma çalışmalarının yoğunlaştırılması,

- Seyahat alışkanlıklarının doğru planlanması,

- Hidrojen ve elektrik enerjisi gibi temiz yakit türlerinin kullanımının yaygınlaştırılması,

- Özel araç kullanımı yerine toplu taşıma araçlarının tercih edilmesi yer almaktadır.

Taşıtlardan kaynaklanan emisyonların azaltılması için alınacak önlemlerle gelecek nesillere daha temiz ve yaşanılabilir bir çevre bırakılması söz konusu olabilecektir.

\section{Kaynaklar}

Açıkgöz, Ş.Ş. (2010). Avrupa Birliği açısından küresel ısınma ve iklim değişikliğine genel bir bakış. Ankara Üniversitesi Avrupa Toplulukları Araştırma ve Uygulama Merkezi, 46. Dönem AB Temel Eğitim Kursu, Ankara.

Aliusta, H., Y1lmaz, B. ve Kırlığlu, H. (2016). Küresel 1sınmayı önleme sürecinde uygulanan piyasa temelli iktisadi araçlar: karbon ticareti ve karbon vergisi. Uluslararası Yönetim Iktisat ve Işsletme Dergisi, 12(12), 382-401.

Alkaya, B. ve Yıldırım, M.A. (2000). Taşıt kaynaklı kirleticilerin azaltılma yöntemleri. Ekoloji Çevre Dergisi, 9(34), 15-20.

Anonim. (2020a). Karbon ayak izi nedir? Erişim adresi http://www.karbonayakizi.com/whatiscarboonfo otprint.html

Anonim. (2020b). Global carbon atlas. Erişim adresi http://www.globalcarbonatlas.org/en/CO2emissi ons

Arı, İ. ve Aydın, L. (2019). Türkiye'de yerel iklim değişikliği eylem planlarının hazırlanması ve etkin uygulanması için öneriler. I $\breve{g} d \imath r$ Üniversitesi Sosyal Bilimler Dergisi, Ek Say1, Aralık, 395-414.

Arıc1, R. (2018). Kağıt-karton geri dönüşüm ürünlerinin karbon ayak izlerinin belirlenmesi. Yüksek Lisans Tezi, İstanbul Üniversitesi Fen Bilimleri Enstitüsü, İstanbul.

Atabey, T. (2013). Karbon ayak izinin hesaplanmast: Diyarbakır örneği. Yüksek Lisans Tezi, Fırat Üniversitesi Fen Bilimleri Enstitüsü, Elazığ.

Ayan, N. (2019). Muğla ilinde yakıt tüketimine bağll karbon ayakizi değişimi. Yüksek Lisans Tezi, 
Yıldız Teknik Üniversitesi Fen Bilimleri Enstitüsü, İstanbul.

Babaoğlu, N. ve Özgünoğlu, K. (2017). Kahramanmaraş havalimanı için uçaklardan kaynaklanan emisyonların belirlenmesi. Kahramanmaraş Sütçü Imam Üniversitesi Mühendislik Bilimleri Dergisi, 20(3), 24-30.

Bekiroğlu, O. (2016). Sürdürülebilir Kalkınmanın Yeni Kuralı: Karbon Ayak İzi. Erişim Tarihi: 06.05.2016. http://www.emo.org.tr.

Biy1k, Y. (2018). Isparta ilinde karayolu kaynakl karbon ayak izinin hesaplanması. Yüksek Lisans Tezi, Süleyman Demirel Üniversitesi Fen Bilimleri Enstitüsü, Isparta.

Bıyık, Y. ve Civelekoğlu, G. (2020). Isparta ilinde karayolu kaynaklı karbon ayak izinin hesaplanması. Bilge International Journal of Science and Technology Research, 4(2), 78-87.

Binboğa, G. ve Ünal, A. (2018). Sürdürülebilirlik ekseninde Manisa Celal Bayar Üniversitesi'nin karbon ayak izinin hesaplanmasına yönelik bir araştırma. Uluslararası İktisadi ve İdari Incelemeler Dergisi, 21, 187-202.

Çelik, HA. (2020). Konya ilinde ulaşımdan kaynaklı karbon ayak izi ve çevresel fayda maliyet analizi. Yüksek Lisans Tezi, Konya Teknik Üniversitesi Lisansüstü Eğitim Enstitüsü, Konya.

Demir, B., Kutlu, B. ve Otay, T. (2015). Okyanuslarda karbon döngüsünde bakterilerin rolü. Bilim ve Gençlik Dergisi, 3(1), 65-76.

Demirbaş, F. (2018). Geri kazanım tesisinde karbon ayak izinin değerlendirilmesi. Yüksek Lisans Tezi, Erciyes Üniversitesi Fen Bilimleri Enstitüsü, Kayseri.

Doğan, S. ve Tüzer, M. (2011). Küresel iklim değişikliği ve potansiyel etkileri. C. $\ddot{U}$. Iktisadi ve Idari Bilimler Dergisi, 12(1), 21-34.

Doğan, AN. (2019). Kumaş boyama, iplik boyama, baskı ve konfeksiyon faaliyetlerinin karbon ayak $i z i$ hesabr. Yüksek Lisans Tezi, Süleyman Demirel Üniversitesi Fen Bilimleri Enstitüsü, Isparta.

Enerji Piyasası Düzenleme Kurumu. (2020a). Petrol piyasası sektör raporlart. Erişim adresi https://www.epdk.gov.tr/Detay/Icerik/3-0107/yillik-sektor-raporu

Enerji Piyasası Düzenleme Kurumu. (2020b). Sıvılaştırılmış petrol gazları (LPG) piyasası sektör raporları. Erişim adresi https://www.epdk.gov.tr/Detay/Icerik/3-0108/lpgyillik-sektor-raporlari
Erdoğan, M. (2015). Çevresel tesislerden kaynaklanan sera gazı emisyonlarının hesaplanması. Yüksek Lisans Tezi, İstanbul Teknik Üniversitesi Fen Bilimleri Enstitüsü, İstanbul.

Gökçek, BÖ., Bozdağ, A. ve Demirbağ, H. (2019). Niğde Ömer Halisdemir Üniversitesi örneğinde karbon ayak izinin belirlenmesi. Nĭ̆de Ömer Halisdemir Üniversitesi Mühendislik Bilimleri Dergisi, 8(2), 721-730.

Güller, S. (2018). Muğla evsel atıksu arttma tesisi karbon ayak izinin değerlendirilmesi. Yüksek Lisans Tezi, Muğla Sıtkı Koçman Üniversitesi Fen Bilimleri Enstitüsü, Muğla.

Intergovernmental Panel on Climate Change (IPCC). (1996). An introduction to simple climate models used in the IPCC second assesment report. IPCC Technical Paper, Geneva, Switzerland, 8-10.

IPCC/UNEP/OECD/IEA. (1997). Revised 1996 IPCC Guidelines for National Greenhouse Gas Inventories Volume III: Reference Manual, Chapter 1 pp 4-44, 62-98, Intergovernmental Panel on Climate Change, United Nations Environment Programme, Organization for Economic CoOperation and Development, International Energy Agency, Paris.

IPCC, 2006. IPCC Guidelines for National Greenhouse Gas Inventories, Volume 2, Chapter 3. Intergovernmentel Panel on Climate Change, Paris.

Kelen, F. (2014). Motorlu taşı1t emisyonlarının insan sağlığı ve çevre üzerine etkileri. Yüzüncü $Y \imath l$ Üniversitesi Fen Bilimleri Enstitüsü Dergisi, 19(1-2), 80-87.

Keskin, SS. Erdil, M. ve Sennaroğlu, B. (2017). Bir tekstil fabrikasının kumaş üretiminde enerji ve karbon ayak izlerinin belirlenmesi. VII. Ulusal Hava Kirliliği ve Kontrolü Sempozyumu, 1-3 Kasım 2017-Antalya.

Kumaş, K., Akyüz, A., Zaman, M. ve Güngör, A. (2019). Sürdürülebilir bir çevre için karbon ayak izi tespiti: MAKÜ Bucak sağlık yüksekokulu örneği. El-Cezeri Journal of Science and Engineering, 6(1), 108-117. https://doi.org/10.31202/ecjse.459478

Misır, N., Misır, M. ve Ülker, C. (2011). Karbon depolama kapasitesinin belirlenmesi. I. Ulusal Akdeniz Orman ve Çevre Sempozyumu, 26-28 Ekim 2011- Kahramanmaraş.

Özçelik, G. (2017). Çanakkale Onsekiz Mart Üniversitesi Terzioğlu kampüsü'nün enerji ve karbon ayak izi açısından değerlendirilmesi. Yüksek Lisans Tezi, Çanakkale Onsekiz Mart Üniversitesi Fen Bilimleri Enstitüsü, Çanakkale. 
Özmen, MT. (2009). Sera gazı-küresel 1sınma ve kyoto protokolü. IMO Dergisi, 453(1), 42-46.

Pekin, MA. (2006). Ulaştırma sektöründen kaynaklanan sera gazl emisyonlarl. Yüksek Lisans Tezi, İstanbul Teknik Üniversitesi Fen Bilimleri Enstitüsü, İstanbul.

Sümer, G.Ç. (2014). Hava kirliliği kontrolü: Türkiye'de hava kirliliğini önlemeye yönelik yasal düzenlemelerin ve örgütlenmelerin incelenmesi. International Journal of Economic and Administrative Studies, 7(13), 37-56. https://doi.org/10.18092/ulikidince.232135

Şahin, G. ve Avcıoğlu, AO. (2016). Tarımsal üretimde sera gazları ve karbon ayak izi. Tarım Makinaları Bilimi Dergisi, 12(3), 157-162.

T.C. Çevre ve Şehircilik Bakanlığı (2019). IPCC özel raporları. Erişim adresi https://cygm.csb.gov.tr/ipcc-ozel-raporlarihaber-248919

T.C. Çevre ve Şehircilik Bakanlığı (2020). Kyoto Protokolü. Erişim adresi http://iklim.csb.gov.tr/kyoto-protokolu-i-4363

T.C. Dişişleri Bakanlığı (2020). Kyoto Protokolü. Erişim adresi http://www.mfa.gov.tr/kyotoprotokolu.tr.mfa
Turanl, MA. (2015). Estimation of carbon footprint: a case study for Middle East Technical University. Master's Thesis, The Graduate School of Natural and Applied Sciences of Middle East Technical University, Ankara.

Türkiye İstatistik Kurumu, 2020. Motorlu Kara Taşıtları. Erişim adresi http://www.oydertr.org/rapor-detayi?hedef $=2176$

Türkay, M. (2018). Karayolu ulaşımından kaynaklanan sera gazl emisyonunun (Karbon ayak izinin) hesaplanması: Eskişehir ili örneği. Yüksek Lisans Tezi, Cumhuriyet Üniversitesi Fen Bilimleri Enstitüsü, Sivas.

Uysal Şahin, Ö. (2016). Kyoto protokolü ve Kopenhag mutabakatının karşılaştırmalı analizi. Journal of Awareness (JoA), 1(1), 5-16.

Uzunçakmak, M. (2014). Ulaşım modlarından kaynaklanan sera gazl emisyonlarl ve iklim değişikliği üzerindeki etkilerinin karşılaştırılması. Ulaştırma ve Haberleşme Uzmanlığı Tezi, Ulaştırma, Denizcilik ve Haberleşme Bakanlığı, Ankara. 